\title{
MYCETOMA IN AN HIV-INFECTED PATIENT
}

\author{
Luiz G. M. Castro, Neusa Y. S. Valente, José Antônio M. Germano, Elisabeth M. \\ Heins Vaccari and Carlos da Silva Lacaz
}

RHCFAP-2986

CASTRO, L. G. M. et al. - Mycetoma in an HIV infected patient. Rev. Hosp. Clin. Fac. Med. S.Paulo 54 (5):169-171,1999.

SUMMARY: Although oportunistic fungal infections occur commonly in immunocompromised hosts, mycetoma has never been reported in association with HIV infection. The authors present a case that to their knowledge is the first reported case of mycetoma associated with HIV infection. Diagnosis was confirmed by direct examination of grains and histologic examination. Precise identification of the agent, an actinomycete, was not possible. The unusual site of infection may probably be related to the use of contaminated needless and sirynges for HIV drug injection.

DESCRIPTORS: Mycetoma. Actinomycete. Fungal infections. HIV.

Fungal infections in HIV-infected patients are a common and potentially life threatening condition. Candidiasis and cryptococcosis occur more frequently in this setting. Subcutaneous mycoses, such as sporotrichosis, have also been reported ${ }^{1,2}$ but are far less frequent. We present a case of mycetoma in an HIV-infected patient, which we believe to be the first reported case of such association.

\section{CASE REPORT}

A 31-year-old black man presented to the University of São Paulo Dermatology Outpatient Service complaining of swelling of the right elbow. Examination disclosed marked local tumefaction, induration, and draining sinuses (Fig. 1). Expression of the lesion yielded white-yellowish, $0.5-1.0 \mathrm{~mm}$, soft grains. Direct examination of $10 \%$ $\mathrm{KOH}$ clarified grains confirmed diagnosis of actinomycetoma. Cultures in Sabouraud agar were repeatedly negative. Histopathology confirmed the previously suspected diagnosis. Delicate actinomycotic filaments were observed

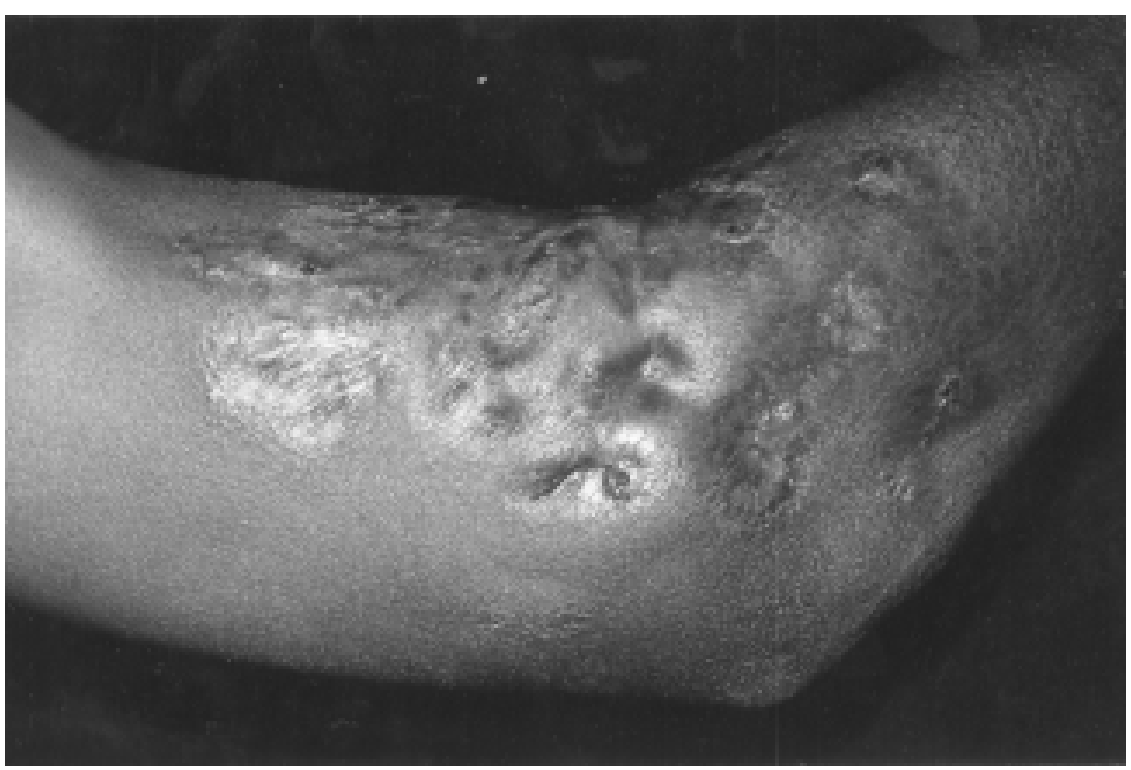

Figure 1 - Typical mycetoma lesion on the right elbow. Two components of the mycetoma triad can be observed: tumefaction and draining sinuses. Grains, the third component of the triad, were observed on direct examination.

inside the round-shaped grains, which were surrounded by an eosinophilic fringe (Höppli-Splendore phenom-

From the Division of Dermatology, University of São Paulo School of Medicine, São Paulo Brazil and Institute of Tropical Medicine, São Paulo - Brazil. enon) in $\mathrm{H}$ \& $\mathrm{E}$ stained sections (Fig.2). Fite-Faraco staining did not demonstrate acid-fast structures.

Therapy with oral trimethoprim/ sulfamethoxazole (TMP/SMZ) $800 \mathrm{mg}$ b.i.d. was started, resulting in quick improvement of tumefaction and healing of sinus tracts. The patient was lost to follow-up. Eight months later he 


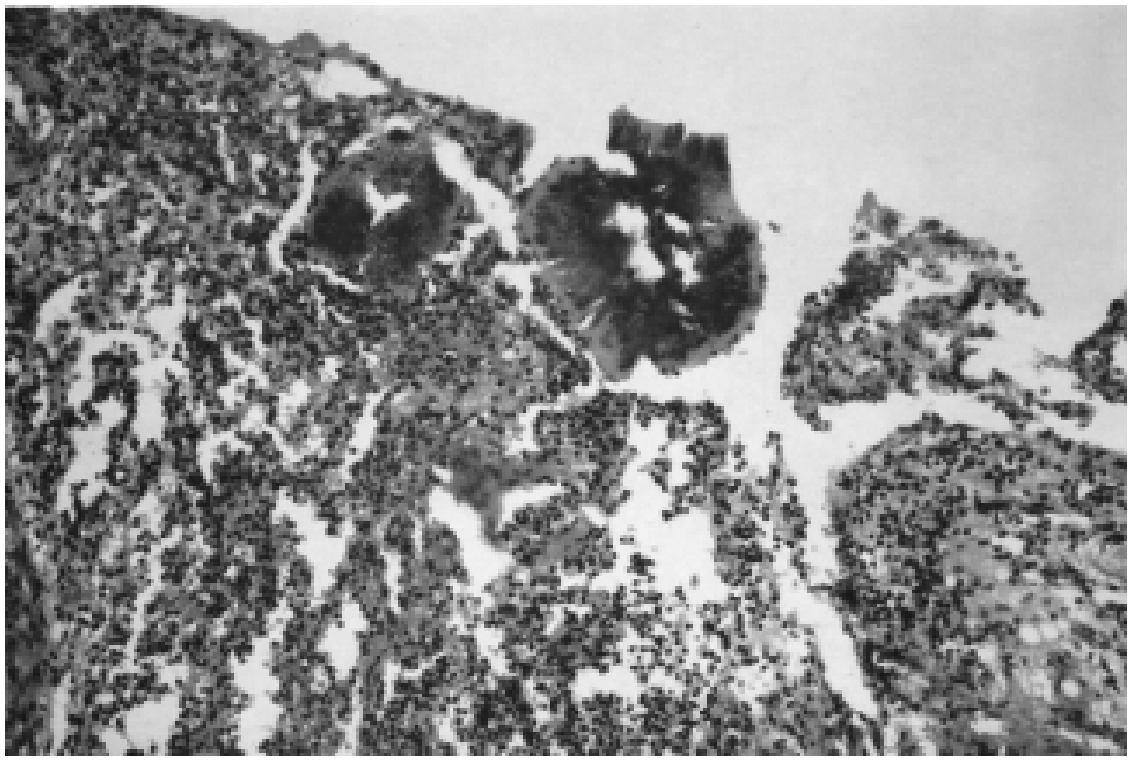

Figure 2 - H \& E stained histologic section showing an actinomycotic grain amidst mixed inflammatory infiltrate. Delicate actinomycotic filaments are inside the round-shaped grain, which has clubs and is surrounded by an eosinophilic fringe (Höppli-Splendore phenomenon) (100X).

presented to the Hospital because of worsening of his condition. The affected limb presented with marked inflammatory changes, and an abscess on the medial aspect of the elbow was evident. The patient reported gradual worsening over the previous months after self-discontinuation of TMP/SMZ therapy.

A new medical history revealed regular IV cocaine use. Surgical drainage of the abscess was performed. White-yellowish grains were present in the purulent secretion. Culture in Sabouraud agar with and without chloramphenicol, potato agar, BHI agar, and soya broth failed to grow aerobic or anaerobic actinomycetes. Direct examination was positive for actinomycotic grains.

The patient tested positive for HIV antibodies by ELISA and Western blotting. There was no evidence of opportunistic infections or neoplasms. Enlarged lymph nodes were palpable in the left axilla. Peripheral blood lymphocyte count was slightly below normal levels (828/mm3). CD4 count was not performed. The patient had an asymptomatic HIV infection, and no in- formation on CD4 count was available. He was tentatively classified as " A" catsification system for HIV infection ${ }^{3}$ and was referred to Infectious Diseases Clinic. Therapy with oral TMP/SMZ $800 \mathrm{mg}$ b.i.d. was restarted. The patient was seen in a follow-up visit 30 days after surgical drainage, presenting marked improvement. He has been lost to follow-up since.

\section{DISCUSSION}

Fungal infections occur commonly in immunocompromised hosts. Certain types of mycoses, however, have rarely been reported in association with HIV infection. To our knowledge this is the first reported case of mycetoma associated with HIV infection. Antinori et al. ${ }^{4}$ reported a case of disseminated Rhodococcus equi infection initially presenting as foot mycetoma in an HIV positive patient. This case was not typical of mycetoma because draining sinuses and grains were not present. The patient reported by Antinori et al. ${ }^{4}$ presented a nodular lesion located on the egory according to "1993 revised clas- right foot, which subsequently disseminated to lymph nodes, lungs, and brain, whereas the present case showed all the typical clinical characteristics of a mycetoma, i.e. tumefaction, draining sinuses, and presence of grains, which are aggregates of the etiologic agent ${ }^{5}$.

Epidemiology of mycetoma in Brazil ${ }^{6}$ differs markedly from that of HIV infection. The former is usually seen in rural areas, is an indolent process, affects men more frequently than women and is a consequence of traumatic implantation of the agent through the skin, whereas HIV infection is more often an urban infection, with a different and characteristic epidemiology. These differences might explain the unusual association of both diseases. It is also interesting to note that actinomycetoma is more frequently observed on the foot ${ }^{5,6}$.

In the present case contaminated needles used for IV cocaine injections can be presumed as possible inoculation vectors of the agent into the upper limb.

In Brazil approximately $75 \%$ of mycetomas are caused by Nocardia $s p .^{6}$, an actinomycete that forms round to multi-lobulated, 40 to $150 \mu$ in diameter white-yellowish grains. Nocardia brasiliensis grains normally show rarefaction of fungal structures in the innermost parts of the grain, whereas clubs are easily observed on the outer edges. These characteristics strongly suggest that the etiologic agent in the present case would be $N$. brasiliensis. On the other hand, the fact that no acid fast structures could be seen in the FiteFaraco stained grains practically excludes this possibility ${ }^{7}$. Additionally, it is uncommon to observe an eosinophilic fringe (Höppli-Splendore phenomenon) in $N$. brasiliensis grains. Finally, $N$. brasiliensis grains are weakly basophilic and easily cultivated, findings not observed in the present case. Special effort was made toward identification of the agent, but cultures 
were repeatedly negative, making it impossible to precisely identify the agent.

We believe this association has been casual. Abscess formation is a rare event in mycetoma patients. The acute worsening of the patient's condition might well be related to his supposedly depressed immunologic status. The marked improvement following surgical drainage and TMP/SMZ oral therapy suggests the infection would respond satisfactorily to therapy. It will be difficult to confirm this impression because the patient has been lost to follow-up.
CASTRO, L. G. M. e col. - Mycetoma em paciente HIV positivo. Rev. Hosp. Clín. Fac. Med. S.Paulo 54 (5):169-171, 1999.

Os autores relatam um caso de actinomicetoma em pacientes HIV positivo. Apesar das infecções fúngicas oportunistas serem freqüentemente observadas em pacientes infectados pelo HIV, a associação com micetoma nunca foi descrita. O diagnóstico foi confirmado pelo exame micolígico direto de grãos obtidos da secreção e de exame anátomo-patológico. Não foi possível identificar o agente, mas as características sugerem tratar-se de actinomiceto. Os autores acreditam que a localização no membro superior possa estar relacionada com o uso de seringas e agulhas contaminadas para injeção de drogas EV.

\section{REFERENCES}

1. JUSTA P NETO R, MACHADO AA, CASTRO G et al. - Acquired immunodeficiency syndrome presenting as disseminated cutaneous sporotrichosis. Rev Bras Med Trop 1999; 32(1):57-61.

2. SHAW JC, LEVINSON W, MONTANARO A - Sporotrichosis in the acquired immunodeficiency syndrome. J Am Acad Dermatol 1989; 21:1145-7.

3. CDC. - 1993 revised classification system for HIV infection and expanded surveillance case definition for AIDS among adolescents and adults. MMWR 1992; 41(\#RR17):1-19.
4. ANTINORI S, ESPOSITO R, CERNUSCHI M et al. - Disseminated Rhodococcus equi infection initially presenting as foot mycetoma in an HIV-positive patient. AIDS 1992;7:740-2.

5. McGINNIS MR, FADER RC - Mycetoma: a contemporary concept. Inf Dis Clin North America 1988; 2:939-54.

6. CASTRO LGM, BELDA JR. W, SALEBIAN A et al. - Mycetoma: a retrospective study of 41 cases seen in São Paulo, Brazil, from 1978 to 1989 . Mykoses 1993;36:89-95.

7. NOVALES J - Contribuición de la dermatopatologia al conocimiento de los micetomas. Med Cut ILA 1995;23:248-52.

Received for publication on the 29/09/99 